\title{
Strain of foster mother determines long-term effects of early handling: Evidence for maternal mediation
}

\author{
MICHAEL B. HENNESSY \\ SRI International, Menlo Park, California \\ JERRY VOGT \\ St. John's University, Collegeville, Minnesota \\ and \\ SEYMOUR LEVINE \\ Stanford University School of Medicine, Stanford, California
}

\begin{abstract}
Inbred $\mathbf{A} / \mathbf{J}$ mice were raised from birth by foster mothers of either the $\mathrm{A} / \mathrm{J}$ or $\mathrm{C57B1/6J}$ strain. Some litters of each maternal rearing condition were handled during the preweaning period, whereas others were not. In adulthood, the behavior of females in the open field as well as the plasma corticosterone levels of males following both no disturbance and placement in a novel environment were examined. Defecation in the open field was found to be greater in handled than in nonhandled subjects, but only for those that had been reared by a C57B1/6J foster mother. Conversely, plasma corticosterone levels were observed to be lower in handled than in nonhandled subjects, but only for those reared by an A/J foster mother. These results provide support for the hypothesis of maternal mediation of long-term effects of differential early stimulation.
\end{abstract}

During the past 25 years, there have been numerous reports that varying the stimulation to which laboratory rodents are exposed during infancy can have dramatic effects on later behavior and physiology. Preweaning mice and rats subjected to handling, shock, chilling, or other forms of manipulation have been found to differ as adults from nonmanipulated controls on various measures, including activity (Denenberg \& Smith, 1963; Levine \& Broadhurst, 1963; Levine, Haltmeyer, Karas, \& Denenberg, 1967), exploration (DeNelsky \& Denenberg, 1967a, 1967b; File, 1978; Weinberg, Krahn, \& Levine, 1978), defecation in stressful situations (Denenberg \& Smith, 1963; Henderson, 1964; Levine \& Broadhurst, 1963), learning (Bell \& Denenberg, 1963; Denenberg \& Bell, 1960; Levine, Chevalier, \& Korchin, 1956), and pituitary-adrenal activity (Ader \& Grota, 1969; Levine et al., 1967; Weinberg \& Levine, 1977). Yet, many

The authors are grateful to Angie Vickers for her able assistance in collecting and summarizing the data and to Helen $\mathrm{Hu}$ for determining plasma corticosterone concentrations. This research was supported by Research Grant HD 02881. Support was provided for M. B. Hennessy by National Research Service Award HD 05678 and Research Grant HD 14591, for J. Vogt by Training Grant MH 15147 and Research Grant MH 35827, and for S. Levine by USPHS Research Scientist Award MH-19936. Address correspondence to Michael B. Hennessy, SRI Developmental Psychobiology Program, Menlo Park, California 94025. basic questions concerning early experience remain to be answered. Negative and conflicting results are not uncommon in this literature, and satisfactory explanations for these are often lacking (Daly, 1973). Moreover, the mechanisms underlying early-experience effects remain the subject of speculation. Some early suggestions, such as that corticosterone released during early stimulation acts on the brain to reduce later emotionality (Denenberg \& Zarrow, 1971) or that the hypothermia induced by the early manipulation accounts for the later effects (Schaefer, Weingarten, \& Towne, 1962), have since fallen into disfavor (e.g., Ader \& Grota, 1973; Thoman \& Levine, 1969).

A hypothesis that has been gaining support in recent years is that the mother's differential treatment of manipulated and nonmanipulated pups mediates at least some early-stimulation effects (Barnett \& Burn, 1967; Meier \& Schutzman, 1968; Richards, 1966). It has been amply demonstrated that maternal behavior varies with the treatment (e.g., handling, shock, nonmanipulation) of the infant mouse or rat (Barnett \& Burn, 1967; Bell \& Little, 1978; Bell, Nitschke, Bell, \& Zachman, 1974; Lee \& Williams, 1975; Priestnall, 1973; Sherrod, Connor, \& Meier, 1974; Smotherman, Brown, \& Levine, 1977; Young, 1965). Early-stimulation procedures also affect the ultrasonic signaling of pups (Bell, Nitschke, Gorry, 
\& Zachman, 1971; Hennessy, Smotherman, Kolp, Hunt, \& Levine, 1978), and such changes in the stimulus properties of the young presumably elicit the alterations in maternal behavior. Furthermore, there is evidence that changes in maternal behavior elicited by cues from manipulated pups can influence the young's development. Schreiber (1978) found that the sensitivity of adult rats to amphetamine depended on whether they and their mother had been exposed to the cues of stimulated, inaccessible pups during the preweaning period. The infant cues were found to alter the mother's treatment of her own offspring, which apparently affected their later responsiveness to amphetamine. Early handling has also been found to affect later responsiveness to amphetamine, but only if the pups are allowed to interact with their mother following the handling procedure (Schreiber, Bell, Kufner, \& Villescas, 1977).

In the present experiment, differences in the maternal environment of mice of two inbred strains were used to help test this hypothesis of maternal mediation. We raised mouse pups of one strain $(A / J)$ from birth with foster mothers of either the same or another strain (C57B1/6J). Separate subgroups of litters in each maternal rearing condition were then handled or left undisturbed. Mothers of the $A / J$ and C57B1/6J strains have been observed to differ in a number of ways in their treatment of recently handled pups (Hennessy, Li, Lowe, \& Levine, 1980). We reasoned that if mothers of these two strains differed in aspects of behavior critical for mediating early-stimulation effects, then the later performance of the offspring should be an interactive function of maternal rearing and early stimulation. That is, the effects of early stimulation should vary with the type of mother rearing the pups. The offspring were examined in adulthood for activity and defecation in the open field, and their plasma corticosterone levels were measured under undisturbed conditions as well as following placement in a novel environment. These measures were chosen because they have been among the most commonly used in tests of earlystimulation effects (Daly, 1973; Denenberg \& Zarrow, 1971).

\section{METHOD}

\section{Subjects and Design}

The subjects were inbred $\mathrm{A} / \mathrm{J}$ mice (Mus musculus) born to parents that had been obtained prior to breeding from Jackson Memorial Laboratories in Bar Harbor, Maine. The mice were maintained on a 12-h-light/12-h-dark cycle (lights on at 0800) and had lab chow and water available continuously. On the day of birth, each experimental litter was adjusted, as closely as possible, to three male and three female pups. When necessary, spare pups from other litters born the same day were used. Each adjusted litter was then given to a newly parturient, primiparous female of either the A/J or C57B1/6J strain. Each foster mother and litter were housed in a separate plastic cage $(28.4 \times 17.8 \times$
$13.3 \mathrm{~cm}$ ) with wood chips for bedding and paper for nesting material. Separate litters of each maternal rearing condition were then assigned to either handling or nonhandling treatments. Thus, four experimental groups were created: $\mathbf{A} / \mathrm{J}$ foster-mother handled (AH), A/J foster-mother nonhandled (AN), C57B1/6J fostermother handled $(\mathrm{CH})$, and $\mathrm{C} 57 \mathrm{~B} 1 / 6 \mathrm{~J}$ foster-mother nonhandled (CN).

\section{Early Stimulation}

From the 2nd through 14th days of life, $\mathrm{AH}$ and $\mathrm{CH}$ litters were subjected once daily to a standard handling procedure (Weinberg et al., 1978; Weinberg \& Levine, 1977). The cage of each handled litter was removed from the rack, the mother was placed in a holding cage, and the pups were placed individually in $6 \times 6 \times 5 \mathrm{~cm}$ cardboard compartments for $3 \mathrm{~min}$. The mother and pups were then returned to the home cage, and it was replaced on the rack. AN and $\mathrm{CN}$ litters were left completely undisturbed until weaning. Their cages were kept apart from those of handled litters on a separate rack that was not moved or otherwise disturbed. No cage was cleaned from birth until weaning at 21 days of age. Groups of littermates were housed together until 30-35 days of age, at which time each subject was housed individually in a plastic cage $(28.4 \times 17.8 \times 13.3 \mathrm{~cm})$ with wood chips for bedding.

\section{Test Procedures}

At 100-120 days of age, a female from each of 8-10 litters in each of the four experimental groups was chosen for open-field testing. The open field was a box $(91.4 \times 91.4 \times 45.7 \mathrm{~cm}$ high) with unpainted wooden sides and a black tile floor. The floor was divided into squares $(15.2 \mathrm{~cm}$ on a side) with thin strips of white tape. At one corner of the apparatus was a $15.2-\mathrm{cm}$ square start chamber that provided access to the main section of the open field through a guillotine door. Each animal was tested in two 3-min sessions conducted on successive days between 1300 and $1700 \mathrm{~h}$ under red illumination. The floor of the open field was cleaned with an ethanol solution between trials to remove odor traces from the previous animal. The latency to leave the start chamber (180 sec maximum), the number of squares entered, and the number of fecal boluses deposited during the $3 \mathrm{~min}$ were recorded.

At 110-130 days of age, blood samples were collected from male subjects to assess resting plasma corticosterone levels and levels following exposure to an unfamiliar environment. This environment was a clean cage of the same type as the home cage, but was without bedding, food, or a water source. Exposure to this environment for brief periods previously has been found to stimulate pituitary-adrenal activity in mice (Hennessy \& Levine, 1978). For each of the four experimental groups, blood samples were collected from a separate squad of five to seven mice at each of the three time points $(0,15$, and $30 \mathrm{~min})$ following exposure to the unfamiliar environment. Each mouse tested at a particular time point was from a different litter. For the 0 -min time point, mice were simply removed from the home cage and blood samples were collected to determine resting corticosterone levels. For the 15- and 30-min time points, mice were placed individually in the unfamiliar environment for the appropriate number of minutes and blood samples were taken. All blood samples were collected and all open-field testing was performed between 0830 and $1100 \mathrm{~h}$. Because our purpose in this experiment was limited to determining whether maternally mediated effects could be demonstrated, we did not require that animals of both sexes be represented in both later tests.

\section{Blood Sampling and Assay Techniques}

To obtain blood samples, mice were decapitated under light ethyl ether anesthesia, and trunk blood was collected in heparinized glass tubes. Samples were obtained within $1 \mathrm{~min}$ of the onset of disturbance. The blood was centrifuged in order to sep- 
arate plasma, which was then extracted and frozen until assay, using the microfluorometric method of Glick, von Redlick, \& Levine (1964).

\section{RESULTS}

Each of the three open-field measures was analyzed with a three-way (maternal rearing $x$ early stimulation $x$ days) analysis of variance, with days treated as a repeated measure. For latency to leave the start chamber, a logarithmic transformation was used to help normalize the distribution of scores prior to analysis. No significant main or interaction effects were found for the analyses of latency to leave the start chamber and number of squares entered. For the defecation measure, a significant maternal rearing $X$ early stimulation interaction was obtained $[F(1,32)=7.17, p<.02]$. Subsequent analysis of the interaction with tests for simple main effects (Winer, 1971) showed that the AH and AN conditions did not differ, but $\mathrm{CH}$ mice deposited significantly more boluses than did $\mathrm{CN}$ mice ( $\mathrm{p}<.01$; see Figure 1$)$. That is, early stimulation affected open-field defecation only if the mice had been reared by a C57B1/6J foster mother. The analysis also yielded a significant effect of days $[F(1,32)=8.03, p<.01]$, indicating an increase from Day 1 to Day 2 in the number of boluses defecated.

A three-way (maternal rearing $x$ early stimulation $x$ time point) analysis of variance of plasma corticosterone data yielded a significant maternal rearing $\times$ early stimulation interaction $[F(1,61)=4.83$, $\mathrm{p}<.05]$. Tests for simple main effects showed that AH mice had significantly lower plasma corticosterone levels than did AN mice $(p<.05$; see Figure 2$)$ but that the $\mathrm{CH}$ and $\mathrm{CN}$ groups did not differ. Thus, early stimulation altered corticosterone levels if the pups were reared by an $\mathrm{A} / \mathrm{J}$ mother, but not if they were reared by a C57B1/6J mother. The finding that

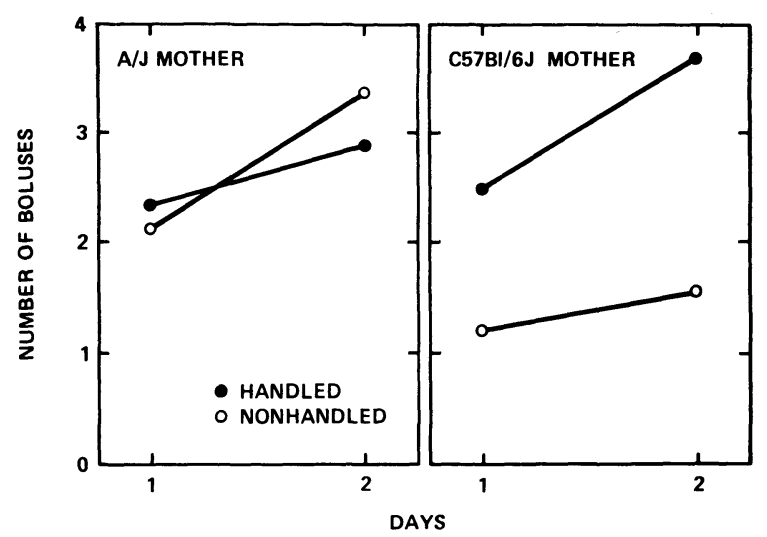

Figure 1. Number of boluses deposited in the open field on Days 1 and 2 in handled and nonhandled $A / J$ mice reared by A/J (left) and C57B1/6J (right) foster mothers.

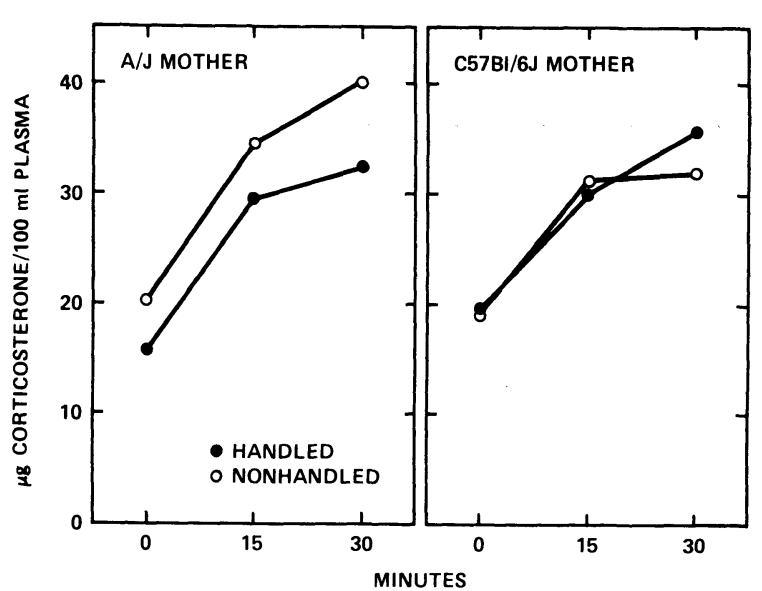

Figure 2. Plasma corticosterone levels following no disturbance $(0)$ as well as 15 and $30 \mathrm{~min}$ after placement in an unfamiliar environment in handled and nonhandled $A / J$ mice reared by $A / J$ (left) and C57B1/6J (right) foster mothers.

the 0 - as well as 15 - and 30 -min levels of corticosterone differed between $\mathrm{AH}$ and $\mathrm{AN}$ mice, together with the absence of a significant three-way interaction, suggests that the observed effect reflects a difference in resting corticoid levels rather than in the response to novelty. The main effect of time point was highly significant, as expected $[\mathrm{F}(2,61)=40.10$, $\mathrm{p}<.001]$.

\section{DISCUSSION}

Each of the handling effects observed in the present experiment occurred when pups were raised by a foster mother of one, but not of the other, strain. This indicates that some characteristic of the maternal environment that varied between the $\mathrm{A} / \mathrm{J}$ and C57B1/6J strains was essential for each of these consequences of early handling. Therefore, our results provide strong support for the hypothesis of maternal mediation of early-stimulation effects (Barnett \& Burn, 1967; Meier \& Schutzman, 1968; Richards, 1966).

In previous studies, early stimulation has been found to reduce pituitary-adrenal activity, both under undisturbed conditions and following placement in a novel environment, and to affect excretion in the open field (Ader, Friedman, Grota, \& Schaeffer, 1968; Ader \& Grota, 1969; Denenberg \& Smith, 1963; Haggett \& Werboff, 1968; Weinberg et al., 1978). The direction of this latter effect appears to vary among rodents, most often being reduced in rats and increased in mice following early stimulation (Daly, 1973; Denenberg \& Smith, 1963; Haggett \& Werboff, 1968; Henderson, 1964; Levine \& Broadhurst, 1963). Thus, the direction of the handling effects that we observed is consistent with earlier work. 
Since handling altered open-field defecation in mice raised with $\mathrm{C} 57 \mathrm{~B} 1 / 6 \mathrm{~J}$ but not $\mathrm{A} / \mathrm{J}$ mothers, and it affected pituitary-adrenal activity in mice raised with mothers of the $A / J$ but not $C 57 B 1 / 6 J$ strains, one might conclude that different aspects of the maternal environment mediate these open-field and pituitary-adrenal effects. However, since females were used in the open-field test and males were used in analysis of corticosterone concentrations, we cannot rule out an alternative hypothesis-that $\mathbf{A} / \mathbf{J}$ mothers tend to mediate early-stimulation effects in males, and C57B1/6J mothers tend to mediate effects in females, regardless of the later test situation. In either case, our results point to maternal mediation effects and suggest that some of the conflicting results reported in the early-stimulation literature (Daly, 1973) might be accounted for by differences in the mothering patterns of the different rodents used in various studies. We do not wish to imply that all early-stimulation effects are maternally mediated. Given the great diversity of effects that have been observed, it would not be surprising if more than one mediating pathway were involved. Moreover, maternal mediation might sometimes consist of an action by the mother on other processes that have been suggested to underlie early-stimulation effects, such as maintenance of pup body temperature.

We have previously found that mothers of these two strains vary in a number of ways in their treatment of recently handled pups (Hennessy et al., 1980). However, it may not be possible to relate specific differences in maternal behavior immediately following handling to specific differences in developmental outcomes. Rather, it may be instructive to consider more closely the mother's behavior and influence on the pups under undisturbed conditions. Earlystimulation effects are necessarily judged in relation to the performance of an undisturbed control group. Note, in Figure 1, that our effect of "handling" appears to result from the C57B1/6J maternal environment under undisturbed conditions (CN group) lowering defecation, as compared with levels seen in each of the other three groups of mice. Perhaps it is under undisturbed conditions that mothering patterns are apt to exert their strongest effects on pup development. Subjecting the young to an early-stimulation procedure might reduce the maternal influence on the offspring. Support for this notion is provided by Treiman, Fulker, and Levine (1970), who examined the effects of handling on corticosterone responses in two inbred strains of mice and their reciprocal crosses. Among nonhandled female offspring, C57B1/ $10 \mathrm{~J}$ and $\mathrm{DBA} / 2$ maternal environments were found to have opposing influences on plasma corticosterone levels. If, however, the female pups had been handled, no maternal influence was observed. Thus, the presence or magnitude of an "early-stimulation effect" might potentially be determined by the strength of the mother's influence in the nonstimulated group, as suggested in Figure 1. That is, maternal mediation of early-stimulation effects may sometimes involve a process whereby the early stimulation merely disrupts an otherwise occurring maternal influence.

\section{REFERENCES}

Ader, R., Friedman, S. B., Grota, L. J., \& Schaefer, A. Attenuation of the plasma corticosterone response to handling and electric shock stimulation in the infant rat. Physiology \& Behavior, 1968, 3, 327-331.

Ader, R., \& Grota, L. J. Effects of early experience on adrenocortical reactivity. Physiology \& Behavior, 1969, 4, 303-305.

Ader, R., \& Grota, L. J. Adrenocortical mediation of the effects of early life experiences. Progress in Brain Research, 1973, 39, 395-406.

BarnetT, S. A., \& Burn, J. Early stimulation and maternal behavior. Nature, 1967, 213, 150-152.

Bell, R. W., \& Denenberg, V. H. The interrelationships of shock and critical periods in infancy as they affect adult learning and activity. Animal Behaviour, 1963, 11, 21-27.

BELL, R. W., \& LitTLE, J. Effects of differential early experience upon parental behavior in Mus musculus. Developmental Psychobiology, 1978, 11, 199-203.

Bell, R. W., Nitschke, W., Bell, N. J., \& Zachman, T. A. Early experience, ultrasonic vocalizations, and maternal responsiveness in rats. Developmental Psychobiology, 1974, 7, 235-242.

Bell, R. W., Nitschke, W., Gorry, T. H., \& Zachman, T. A. Infantile stimulation and ultrasonic signaling: A possible mediator of early handling phenomena. Developmental Psychobiology, 1971, 4, 181-191.

DALY, M. Early stimulation of rodents: A critical review of present interpretations. British Journal of Psychology, 1973, 64, 435-460.

DeNelsky, G. Y., \& Denenberg, V. H. Infantile stimulation and adult exploratory behavior: Effects of handling upon tactual variation seeking. Journal of Comparative and Physiological Psychology, 1967, 63, 309-312. (a)

DeNelsky, G. Y., \& Denenberg, V. H. Infantile stimulation and adult exploratory behaviour in the rat: Effects of handling upon visual variation seeking. Animal Behaviour, 1967, 15, 568-573. (b)

Denenberg, V. H., \& Bell, R. W. Critical periods for the effects of infantile experience on adult learning. Science, 1960, 131, 227-228.

Denenberg, V. H., \& Smith, S. A. Effects of infantile stimulation and age upon behavior. Journal of Comparative and Physiological Psychology, 1963, 56, 307-312.

Denenberg, V. H., \& Zarrow, M. X. Effects of handling in infancy upon behavior and adrenocortical activity: Suggestions for a neuroendocrine mechanism. In D. N. Walcher \& D. L. Peters (Eds.), Early childhood: The development of self-regulatory mechanisms. New York: Academic Press, 1971.

File, S. The ontogeny of exploration in the rat: Habituation and effects of handling. Developmental Psychobiology, 1978, 11, 321-328.

Glick, D., von Redlich, D., \& Levine, S. Fluorometric determination of corticosterone and cortisol in 0.02-0.05 milliliters of plasma or submilligram samples of adrenal tissue. Endocrinology, 1964, 74, 653-655.

HAGgett, B. N., \& WerbofF, J. Temperature reduction in neonatal mice: Effects on later behavior. Developmental Psychobiology, 1968, 1, 257-265.

Henderson, N. D. Behavioral effects of manipulation during different stages in the development of mice. Journal of Comparative and Physiological Psychology, 1964, 57, 284-289.

Hennessy, M. B., \& Levine, S. Sensitive pituitary-adrenal re- 
sponsiveness to varying intensities of psychological stimulation. Physiology \& Behavior, 1978, 21, 295-297.

Hennessy, M. B., Li, J., Lowe, E. L., \& Levine, S. Maternal behavior, pup vocalizations, and pup temperature changes following handling in mice of 2 inbred strains. Developmental Psychobiology, 1980, 13, 573-584.

Hennessy, M. B., Smotherman, W. P., Kolp, L. A., Hunt, L. E., \& Levine, S. Stimuli from pups of adrenalectomized and malnourished female rats. Physiology \& Behavior, 1978, 20, 509-513.

LeE, M. H. S., \& Williams, D. I. Long-term changes in nest condition and pup grouping following handling of rat litters. Developmental Psychobiology, 1975, 8, 91-95.

Levine, S., \& Broadhurst, P. L. Genetic and ontogenetic determinants of adult behavior in the rat. Journal of Comparative and Physiological Psychology, 1963, 56, 423-428.

Levine, S., Chevalier, J. A., \& Korchin, S. J. The effects of early shock and handling on later avoidance conditioning. Journal of Personality, 1956, 24, 475-493.

Levine, S., Haltmeyer, G. C., Karas, G. G., \& Denenberg, V. H. Physiological and behavioral effects of infantile stimulation. Physiology \& Behavior, 1967, 2, 55-59.

Meier, G. W., \& Schutzman, L. H. Mother-infant interactions and experimental manipulation: Confounding or misidentification? Developmental Psychobiology, 1968, 1, 141-145.

Priestnal, R. Effects of handling on maternal behaviour in the mouse (Mus musculus): An observational study. Animal Behaviour, 1973, 21, 383-386.

RIChARDS, M. P. M. Infantile handling in rodents: A reassessment in the light of recent studies of maternal behaviour. Animal Behaviour, 1966, 14, 582.

Schaefer, T., Weingarten, F. S., \& Towne, J. C. Temperature change: The basic variable in the early handling phenomena? Science, 1962, 135, 41-42.
Schreiber, H. L. Maternal behavior and offspring amphetamine response. Unpublished doctoral dissertation, Texas Tech University, 1978.

Schreiber, H. L., Bell, R. W., Kufner, M., \& Villescas, R. Maternal behavior: A determinant of amphetamine toxicity in rats. Psychopharmacology, 1977, 52, 173-176.

Sherrod, K. B., Connor, W. H., \& Meier, G. W. Transient and enduring effects of handling on infant and maternal behavior in mice. Developmental Psychobiology, 1974, 7, 31-37.

Smotherman, W. P., Brown, C. P., \& Levine, S. Maternal responsiveness following differential pup treatment and motherpup interactions. Hormones and Behavior, 1977, 8, 242-253.

Thoman, E. B., \& Levine, S. Role of maternal disturbance and temperature change in early experience studies. Physiology \& Behavior, 1969, 4, 143-145.

Treiman, D. M., Fulker, D. W., \& Levine, S. Interaction of genotype and environment as determinants of corticosteroid response to stress. Developmental Psychobiology, 1970, 3, 131-140.

Weinberg, J., Krahn, E. A., \& Levine, S. Differential effects of handling on exploration in male and female rats. Developmental Psychobiology, 1978, 11, 251-260.

Weinberg, J., \& Levine, S. Early handling influences on behavioral and physiological responses during active avoidance. Developmental Psychobiology, 1977, 10, 161-169.

Wine R, B. J. Statistical principles in experimental design. New York: McGraw-Hill, 1971.

YounG, R. D. Influence of neonatal treatment on maternal behavior: A confounding variable. Psychonomic Science, 1965, 3, 295-296.

(Manuscript received July 24, 1981; revision accepted for publication September 2, 1981.) 